\title{
CRANIOPLASTIIA PRIMÁRIA NOS AFUNDAMENTOS DO CRÂNIO COM FERIMENTO ABERTO DO COURO CABELUDO
}

\author{
Darcy de Freitas Vellutini * \\ Almir Ferreira de ANDrade * * \\ Roberto Paulo de araujo*
}

\begin{abstract}
O problema do tratamento das falhas ósseas cranianas já foi exaustivamente estudado por vários autores e, entre nós, por Pereira e col. ${ }^{1}$, mostrando as vantagens e desvantagens dos vários materiais empregados. O metilmetacrilato é a substância que reune, no momento, as maiores vantagens para fins de cranioplastias.
\end{abstract}

Com relação à época em que deve ser realizada a cranioplastia, a maioria dos autores é favorável a que ela seja feita em uma seguı:da intervenção, a fim de diminuir a possibilidade de infecção. Alguns autores, porém, como Rietz ${ }^{2}$, são favoráveis ao uso do metilmetacrilato em uma única intervenção cirúrgica.

Em 1968 iniciamos a correção dos afundamentos e a cranioplastia em ferimentos crânio-encefálicos abertos, em uma única intervenção cirúrgica. A finalidade dêste trabalho é mostrar os resultados por nós obtidos neste tipo de tratamento.

MATERIAL E METODOS

Nosso material consta de 13 casos de afundamentos cranianos, rom ferimento aberto do couro cabeludo, nos quais foram realizadas, de imediato e em uma única intervenção cirúrgica, a correção do afundamento e a cranioplastia; 11 casos foram operados no Instituto Paulista de Pronto Socorro e dois no Hospital das Clínicas da Faculdade de Medicina da Universidade de São Paulo. Os dados relativos aos pacientes operados estão resumidos nas tabelas 1 e 2 . A idade dos pacientes variou de 8 a 54 anos, sendo 9 do sexo masculino e 4 do feminino. Em 9 casos havia afundamento frontal; parietal em dois; parieto-temporal em um e parieto-occipital em um. Em 5 casos o afundamento interessava apenas a tábua óssea; em três casos havia também lesão da dura-mater; em 5 casos havia comprometimento do parênquima cerebral. Quanto ao tipo de operação, foram feitas cranioplastias simples em 5 casos e cranioplastias precedidas de plástica de dura-mater em 8. $O$ seguimento dêsses pacientes, no pós-operatório, variou de dois meses a dois anos. A cranioplastia com metilmetacrilato * foi feita segundo a técnica de Woringer e col. ${ }^{3}$, modificada por Pereira e col.': aplicação da pasta obtída pela mistura do monômero com o polímero sôbre a falha óssea, sem proteção dos iecidos subjacentes; não foi feita a fixação da prótese com fios de aço.

Departamento de Neurologia da Faculdade de Medicina da Universidade de São Paulo (Prof. Horácio M. Canelas); * Assistentes; ** Estagiário.

* Material fornecido por Artigos Odontológicos Clássico Ltda. 


\section{RESULTA DOS}

Não tivemos problemas de infecção no pós-operatório imediato. No pós-operatório tardio, em três pacientes (casos 5, 11 e 13), ocorreu pequena colecão sob o retalho, aparecendo de um a dois meses depois da intervenção cirúrgica e que cedeu após sua retirada por meio de punção. Em nenhum caso, até o momento, ocorreu fenômeno de rejeição da prótese que obrigasse à retirada da mesma.

\section{COM ENT TÁ R IOS}

A grande maioria dos autores defende a realização da cranioplastia em um segundo tempo, argumentando que o uso de uma substância estranha ao organismo - o metilmetacrilato, no caso - aumentaria a possibilidade de infecção local e, como conseqüência, a rejeição da peça acrílica. $\mathrm{Na}$ prática, porém, essas suposições não se confirmaram e, em nenhum dos nossos 13 casos operados por essa técnica foi assinalado, durante o seguimento, qualquer fenômeno de infecção local ou de rejeição, apesar de ter havido, em 8 casos, lesão da dura-mater e/ou do tecido cerebral. E interessante assinalar que, nos casos 5,11 e 13 nos quais houve formação tardia de coleção sob o retalho, a punção colheu líquido citrino esteril; nestes três casos os pacientes referiram ter sofrido traumatismo na região operada. Estes resultados autorizam a continuar o emprêgo dessa técnica pois, com ela, conseguimos eliminar um tempo cirúrgico e, assim, beneficiar o paciente.

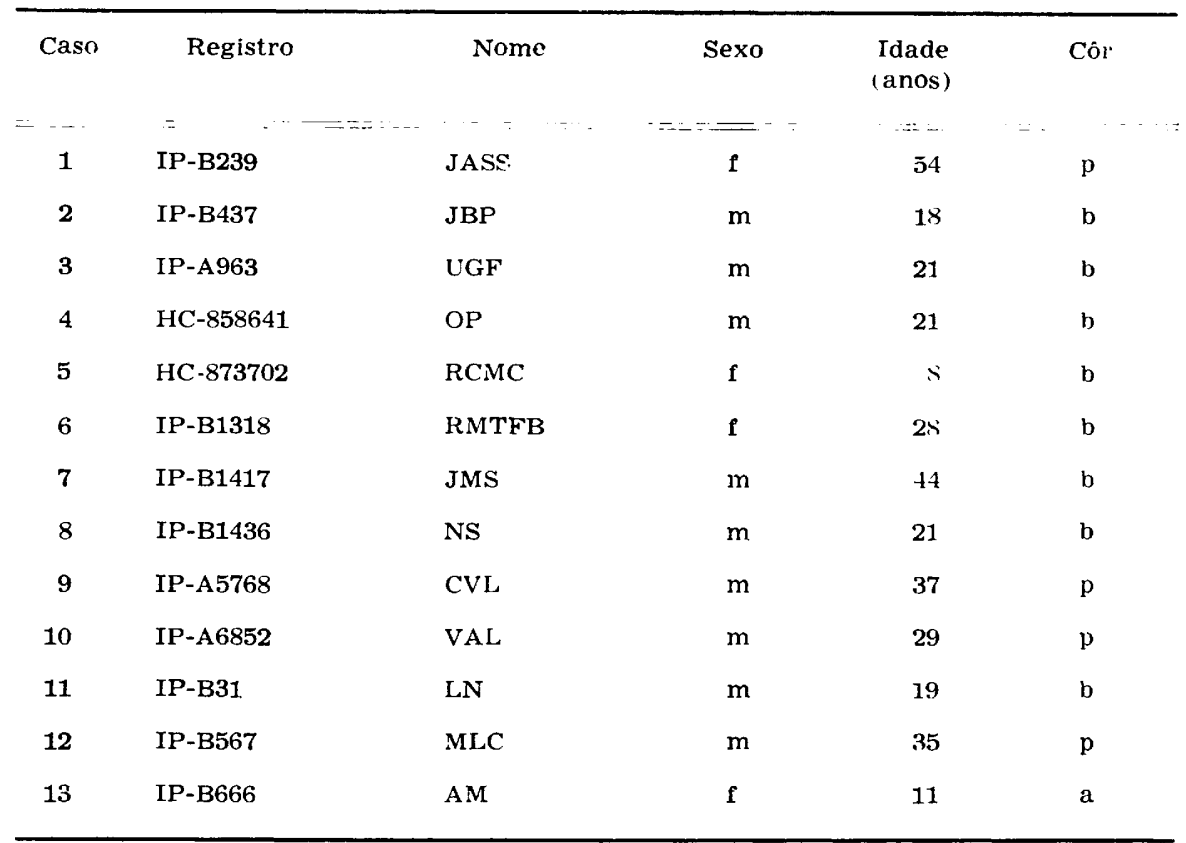

Quadro 1 - Identificacão dos 13 pacientes com traumatismo craniano agudo. Legendas: $H C=$ Hospital das Clinicas; $I P=$ Instituto Paulista de Pronto Socorro; $b=$ branco; $p=$ preto e/ou pardo; $a=$ amarelo. 


\begin{tabular}{|c|c|c|c|c|c|c|}
\hline \multirow[t]{2}{*}{ Caso } & \multirow{2}{*}{$\begin{array}{c}\text { Data de } \\
\text { admissāo e } \\
\text { operação }\end{array}$} & \multicolumn{2}{|r|}{ Afundamento } & \multirow[t]{2}{*}{ Tipo de operação } & \multirow{2}{*}{$\begin{array}{l}\text { Data da } \\
\text { alta }\end{array}$} & \multirow{2}{*}{$\begin{array}{l}\text { Tempo de } \\
\text { seguimento }\end{array}$} \\
\hline & & Sede & Tipo & & & \\
\hline 1 & $30-1-68$ & Frontal & $\begin{array}{l}\text { Afundamento com dilaceração } \\
\text { da dura-mater }\end{array}$ & $\begin{array}{l}\text { Retirada dos fragmentos ósseos }+ \text { plás- } \\
\text { tica da dura-mater }+ \text { cranioplastia }\end{array}$ & $6-2-68$ & 7 meses \\
\hline 2 & $25-2-68$ & $\begin{array}{l}\text { Parieto- } \\
\text { occlpital }\end{array}$ & $\begin{array}{l}\text { Afundamento com dilaceração } \\
\text { da dura-mater e de tecido } \\
\text { cerebral }\end{array}$ & $\begin{array}{l}\text { Retirada dos fragmentos osseos }+ \text { plás- } \\
\text { tica da dura-mater }+ \text { cranioplastla }\end{array}$ & $2-3-68$ & 7 meses \\
\hline 3 & $26-3-68$ & Frontal & $\begin{array}{l}\text { Afundamento com dilaceração } \\
\text { da dura-mater e de tecido } \\
\text { cerebral }\end{array}$ & $\begin{array}{l}\text { Retirada dos fragmentos ósseos }+ \text { plás- } \\
\text { tica da dura-mater }+ \text { cranioplastia }\end{array}$ & $10-4-68$ & 7 meses \\
\hline 4 & $1-4-68$ & Frontal & $\begin{array}{l}\text { Afundamento com dilaceraçāo } \\
\text { da dura-mater, seio sagital } \\
\text { superior e de tecido cerebral }\end{array}$ & $\begin{array}{l}\text { Retirada dos fragmentos ósseos + sutura } \\
\text { do seio sagital + plástica da dura- } \\
\text {-mater + cranioplastia }\end{array}$ & $9-4-68$ & 1 ano \\
\hline 5 & $7-10-68$ & Frontal & $\begin{array}{l}\text { Afundamento com dilaceraçãc } \\
\text { da dura-mater }\end{array}$ & $\begin{array}{l}\text { Retirada dos fragmentos ósseos }+ \text { plás- } \\
\text { tica da dura-mater }+ \text { cranioplastia }\end{array}$ & $11-10-68$ & 2 anos \\
\hline 6 & $22-8-70$ & Frontal & Afundamento simples & $\begin{array}{l}\text { Retirada dos fragmentos ósseos }+ \text { cra- } \\
\text { nioplastia }\end{array}$ & $1-9-70$ & 3 meses \\
\hline 7 & $14-9-70$ & Frontal & Afundamento simples & $\begin{array}{l}\text { Retirada dos fragmentos ósseos + cra- } \\
\text { nioplastia }\end{array}$ & $23-9-70$ & 3 meses \\
\hline 8 & $18-9-70$ & Parietal & $\begin{array}{l}\text { Afundamento com dilaceração } \\
\text { da dura-mater }\end{array}$ & $\begin{array}{l}\text { Retirada dos fragmentos } \delta \text { sseos + sutura } \\
\text { da dura-mater }+ \text { cranioplastia }\end{array}$ & $29-9-70$ & 3 meses \\
\hline 9 & $25-9-70$ & Frontal & Afundamento simples & $\begin{array}{l}\text { Retirada dos fragmentos ósseos }+ \text { cra- } \\
\text { nioplastia }\end{array}$ & $6-10-70$ & 2 meses \\
\hline 10 & $14-11-70$ & $\begin{array}{l}\text { Parieto- } \\
\text { temporal }\end{array}$ & $\begin{array}{l}\text { Afundamento com dilaceração } \\
\text { da dura-mater e de tecido } \\
\text { cerebral }\end{array}$ & $\begin{array}{l}\text { Retirada dos fragmentos osseos }+ \text { plás- } \\
\text { tica da dura-mater }+ \text { cranioplastia }\end{array}$ & $5-12-70$ & 1 mês \\
\hline 11 & $7-1-71$ & Frontal & Afundamento simples & $\begin{array}{l}\text { Retirada dos fragmentos ósseos }+ \text { cra- } \\
\text { nioplastia }\end{array}$ & $16-1-71$ & 2 meses \\
\hline 12 & $9-4-71$ & Parietal & Afundamento simples & $\begin{array}{l}\text { Retirada dos fragmentos ósseos }+ \text { cra- } \\
\text { nioplastia }\end{array}$ & $11-4-71$ & 2 meses \\
\hline 13 & $28-4-71$ & Frontal & $\begin{array}{l}\text { Afundamento com dilaceração } \\
\text { da dura-mater e de tecido } \\
\text { cerebral }\end{array}$ & $\begin{array}{l}\text { Retirada dos fragmentos osseos }+ \text { plás- } \\
\text { tica da dura-mater }+ \text { cranioplastia }\end{array}$ & $15-5-71$ & 4 meses \\
\hline
\end{tabular}

Quadro 2 - Dados clínicos e cirúrgicos dos pacientes com traumatismo craniano agudo. 


\section{R E S M O}

Os autores referem 13 casos de afundamentos crânio-encefálicos pós-traumáticos com ferimento aberto do couro cabeludo nos quais foi usado o metilmetacrilato em uma única intervenção cirúrgica. A sede do afundamento era frontal em 9 casos, parietal em dois, parieto-temporal em um e parieto-occipital em um. Os afundamentos interessavam apenas a tábua óssea em 5 casos, estavam associados a lesão de dura-mater em três e também do tecido cerebral em 5 . Foi realizada cranioplastia simples em 5 casos e, em 8, ela foi precedida de plástica de dura-mater. O seguimento pós-operatório variou de dois meses a dois anos; até o momento não foi assinalada ocorrência de infecção ou de fenômeno de rejeição da prótese que obrigasse a sua retirada.

\section{S U M M A R Y}

Primary cranioplasty in open depressed fractures of the skull.

Thirteen cases of open depressed fractures of the skull in which methylmethacrylate was primarily used are reported. The site of the depressed fractures was frontal in 9 cases, parietal in two, parieto-temporal in one and parieto-occipital in one. In 5 cases, only the bone was injured; in three cases dura mater was damaged; in 5 cases brain and dura mater were damaged. In 5 cases, only a cranioplasty was performed and in 8 cases a dura mater graft was associated. The follow-up was from two months to two years without any complication as infection or rejection of the methylmethacrylate.

\section{REFERENCIAS}

1. PEReira, W. C.; Tenuto, R. A. \& Vellutini, D. F. - Cranioplastias e correção de rinoliquorréias com metilmetacrilato. Considerações a propósito de 35 casos. Arq. Neuro-Psiquiat. (São Paulo) 29:165, 1965.

2. RIETZ, K. - The one-stage method of cranioplasty with acrylic plastic. With a follow-up study. J. Neurosurg. 15:176, 1958.

3. WORINGER, E.; SCHWIEG, G. \& SCHNEIDER, J. - Nouvelle technique ultrarapide pour la réfection de breches osseuses craniennes à la résine acrylique. Avantages de la résine acrylique sur le tantale. Rev. neurol. (Paris) 85:527, 1951.

Clínica Neurológica - Faculdade de Medicina - Universidade de São Paulo Caixa Postal 3461 - 01000 São Paulo SP - Brasil. 